\title{
HOTEL HIJAU SEBAGAI ALTERNATIF PENGURANGAN DAMPAK LINGKUNGAN
}

\author{
Nanny Roedji Nandari \\ Program Diploma Kepariwisataan Universitas Merdeka Malang \\ Jl. Bandung No. 1 Malang
}

Korespodensi dengan Penulis:

Nanny Roedji Nandari: Telp: 081215591418

E-mail: nannyroedjinandari@yahoo.com

\begin{abstract}
Nowadays, eviromental management has gotten a fully attention. Then, hospitality industry in East Java Province has committed to the Eco Friendly Enviroment needs a deep investigation in order to analyze a practical managment of hotel product which uses an eviromental friendly method in improving efficiency of energy, water, air quality, and solid waste management and liquid waste management system. This research used a descriptive qualitatif method which chracterized causuality and using a survey method. Data were collected by using an istitutional-perceptional approach and were analyzed by using enviromental performance scale from 1 to 5 point toward Green Hotel practice. The conclusion from the investigation result are; $45 \%$ hotel understand the concept and green product implementation. 50\% hotel reuse the water to pour the garden. $40 \%$ about operating procedure such as towel reuse and bed sheet. $90 \%$ of the hotel already use VRV air-conditioner which can adjust the temperature suitable with the number of the people in the room and its automatically turn off when there are no people in the room. $45 \%$ shows that hotel provide dispenser to combine shampoo and conditioner (hair moisturizer) in one product so it will decrease the plastic waste.
\end{abstract}

Keyword: Green Hotel, Enviromental Impact

\begin{abstract}
Abstraksi
Pengelolahan lingkungan saat ini menjadi perhatian serius, demikian pula industri perhotelan di Jawa Timur yang berkomitmen terhadap ramah lingkungan yang tidak terlalu banyak sehingga dibutuhkan investigasi ilmiah bertujuan untuk menganalisis praktek pengelolahan produk hotel dengan ramah lingkungan yang di sebut Hotel Hijau dalam rangka peningkatan efisiensi energi, efisiensi air, kualitas udara, dan sistem pengelolaan limbah padat dan limbah cair. Metode penelitian ini berjenis
\end{abstract}


deskriptive kualitatif, bersifat kausalitas, dengan pendekatan menggunakan metode survey. Data yang dikumpulkan menggunakan pendekatan persepsional-institusi. Data diolah dengan skala penilaian kinerja lingkungan bagi hotel dari nilai 1 sampai dengan 5 poin terhadap praktek Green Hotel. Hasil investigasi dapat di simpulkan sebagai berikut ; Sebesar $45 \%$ hotel memahami terhadap konsep dan implementasi green product Sebesar $50 \%$ hotel menggunakan kembali air untuk penyiraman taman. Sebesar $40 \%$ himbauan manajemen hotel seperti dalam penggunaan kembali handuk dan sprei tempat tidur. Sebagian besar $90 \%$ hotel sudah menggunakan pendingin ruangan berjenis VRV air-condition yang dapat mengatur suhu sesuai jumlah orang dalam ruangan dan otomatis mati jika tidak ada orang. Sebesar $45 \%$ hotel menyediakannya dispenser untuk menggabungkan shampo dan conditioner (pelembab rambut) dalam satu produk sehingga tidak akan menambah sampah plastik.

Kata Kunci: Hotel Hijau, Dampak Lingkungan 
Kesadaran pengelolahahan lingkungan telah mengalami perkembangan. Dari hasil survey tahun 2008 menurut National Leisure Survei Travel, kebanyakan wisatawan berharap terhadap kepedulian lingkungan (Crocker, 2008) dan 34\% dari wisatawan yang disurvei menginginkan hotel yang ramah lingkungan, dan 38\% manajemen hotel telah menyediakan fasilitas hijau (Clausing, 2008). Jika banyak wisatawan bertujuan bisnis maupun rekreasi benar-benar peduli lingkungan, maka ada kemungkinan bahwa sikap mereka dan preferensi berpusat pada produk wisata hijau dan jasa yang ramah lingkungan.

Jika wisatawan lebih memilih hotel yang membuat upaya mengurangi dampak terhadap lingkungan, mereka mungkin memiliki pengalaman keseluruhan yang sesuai dengan sikap pribadi mereka sebagai gaya hidup. Jika para pelaku bisnis perhotelan menyadari hal ini, mereka bisa membuat produk mereka menyediakan fasilitas ramah lingkungan untuk menarik wisatawan.
Hotel di Indonesia yang komitmen terhadap ramah lingkungan tidak banyak. Karena sedikitnya pemahaman terhadap Green Hotel yaitu hotel yang memiliki konsep untuk mempraktikkan kesadaran terhadap kualitas lingkungan, hal ini jika dibiarkan akan akan berakibat buruk terhadap lingkungan atau jalannya sustainable development (pembangunan keberkelanjutan). Masalah tersebut disampaikan oleh Menteri Pariwisata dan Ekonomi Kreatif (Kemenpar,2013 ) Kementtrian Pariwisata dalam acara National Green Hotel Award 2011 dan menyatakan bahwa di Indonesia masih banyak hotel yang tidak paham terhadap konsep Hotel Hijau . Banyak hotel berbintang 4 dan 5 yang berdiri di Indonesia dan belum memahami konsep Hotel Hijau . Hal ini penting mengingat Hotel Hijau yang merupakan bentuk kepedulian terhadap lingkungan dan pembangunan pariwisata yang berkelanjutan (Ni Luh, 2013).

Bukti lain menunjukkan bahwa Kementerian Pariwisata dan Ekonomi Kreatif yaitu Mari Elka Pangestu mencoba memberikan penghargaan 
Green Hotel Award di Indonesia yang berwawasan lingkungan dan kepariwisataan yang berkelanjutan. Akan tetapi, penghargaan yang pertama kalinya diberikan itu ternyata kurang mendapat respon yang positif oleh 290 hotel. Dari jumlah tersebut, hanya 76 hotel yang menyatakan kesediaan atau keikutsertaan. Dari 76 hotel itupun hanya 32 yang lolos verifikasi awal. Artinya, hotel yang betul-betul menjalankan Green Hotel hanya 31 hotel yang bersedia didatangi oleh tim penilai sebagai tahap penilaian hotel sebagai perusahaan ramah lingkungan dan berkelanjutan (Ni Luh, 2013).

Hotel-hotel di Indonesia meskipun tidak sepenuhnya mendapatkan sertifikasi sebagai Hotel Hijau setidaknya mulai berpikir tentang konsep-konsep ramah lingkungan. Jika hotel peduli pada lingkungan, otomatis juga peduli pada tamunya. Beberapa hotel memang telah memiliki reputasi sebagai Hotel Hijau . Biasanya hotelhotel ini telah mendapatkan penghargaan atau sertifikasi.

Berdasarkan jumlah kamar yang tersedia untuk seluruh hotel bintang yang ada di Provinsi Jawa Timur, jumlahnya mencapai 12.330 kamar yang bertaraf standar dengan ketersediaan tempat tidurnya sebanyak 19.980 buah, sementara suite ada sebanyak 103 dengan jumlah tempat tidur 103 buah. Pada hotel non bintang tersedia kamar sebanyak 28.568 dengan jumlah tempat tidur 42.028 buah yang bertaraf standar, untuk kamar suite ada 205 dengan tempat tidur yang tersedia sebanyak 205 buah.

Pada tahun 2014 Tingkat Penghunian Kamar (TPK) untuk hotel bintang sebesar 39,33 persen dengan Rata rata Lama Menginap Tamu (RLMT) selama 2,99 hari untuk tamu asing dan 1,86 hari untuk tamu nusantara. Ini menunjukkan bahwa pada tahun 2014 rata-rata dari 100 kamar yang tersedia pada hotel bintang ada sebanyak 39 hingga 40 kamar di antaranya telah terjual setiap malamnya, yang diikuti dengan lamanya menginap tamu asing antara 2 hingga 3 hari dan selama 1 hingga 2 hari untuk tamu domestik. Maka tujuan penulisan artikel ini adalah untuk menganalisis aspek Green Hotels terhadap pengelolaan 
lingkungan dan sumberdaya hotel untuk peningkatan efisiensi energi, efisiensi air, kualitas udara, dan sistem pengelolaan limbah padat dan limbah cair.

\section{METODE}

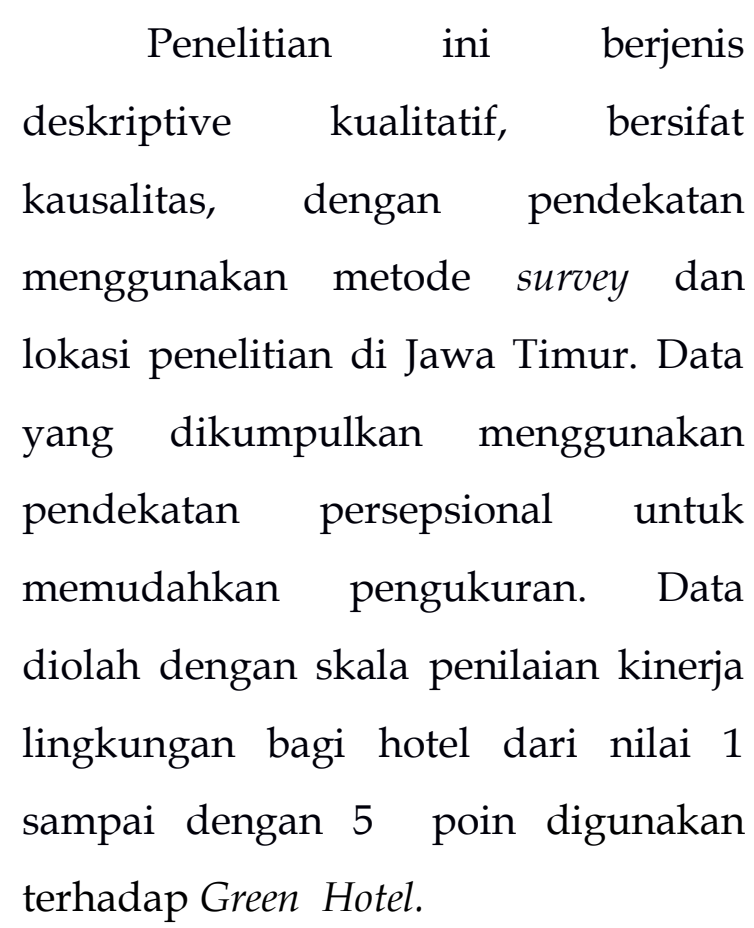

\section{HASIL PENELITIAN DAN}

PEMBAHASAN

Propinsi Jawa Timur memiliki potensi industri pariwisata yang besar dengan rata-rata persentase perkembangan jumlah hotel keseluruhan baik melati maupun bintang adalah 9,54\%. Perkembangan hotel berbintang di Jawa Timur adalah $16.7 \%$ dan merupakan pekembangan hotel yang paling tinggi. Perkembangan wisatawam nusantara
(Wisnus) pada tahun 2013 sejumlah 39.663.005 dan wisman mancanegara 300.090 wisman, naik sebesar $11.78 \%$ dibanding pada tahun 2012 yang jumlahnya 269.943. Lama tinggal wisnus adalah 1.7 hari tinggal sedangkan wisman lebih lama yaitu selama 2.5 hari. Jawa Timur memiliki pintu masuk wisatawan mancanegara yaitu Bandara Juanda dengan urutan ke 5 dalam kontribusi masuknya wisatawan mancanegara ke Indonesia 2.56\% setelah Bandara Tanjung Uban (Bintan - Riau) 3.61\%, dengan demikian pihak pemerintah perlu memperhatikan hotel yang memiliki kepedulian lingkungan untuk diberi reword.

\section{Sebesar $40 \%$ Beberapa hotel} dengan baik menggunakan kembali air bekas mandi untuk menyiram tanaman. $75 \%$ Hotel ramah lingkungan memiliki kebijakan bebas dari asap rokok. $40 \%$ Hotel-hotel menempatkan kartu-kartu imbauan seperti penggunaan kembali handuk dan sprei tempat tidur sehingga handuk dan sprei tempat tidur tidak perlu diganti setiap hari. Dengan demikian tamu cukup minta dirapikan kembali. 30\% hotel yang memiliki 
lantai-lantai khusus bebas rokok. Sebagian tamu dapat memilih menginap di kamar yang berada di lantai tanpa asap rokok. Dan 30\% Hotel menerapkan hemat energi dan masih dsebagian hotel konservatif masih suka menggunakan lampu pijar. Begitu pula penggunaan pendingin ruangan (AC). Dan 80\% Hotel menggunakan pendingin ruangan berjenis VRV air-condition yang dapat mengatur suhu sesuai jumlah orang dalam ruangan dan otomatis mati jika tidak ada orang.

Sebesar $80 \%$ hotel memiliki keasrian taman atau banyak tanaman. Taman-taman hijau berfungsi untuk membersihkan udara sekitar hotel. Penggunaan air untuk menyiram tanaman yang dilakukan pihak hotel menggunakan air bekas mandi yang diolah untuk menyiram tanaman. Dan masih sedikit Hotel menyediakan dispenser untuk sabun dan shampo. Seharusnya Hotel Hijau menyediakannya dalam dispenser atau wadah isi ulang dan mengabungkan shampo dan conditioner (pelembab rambut) dalam satu produk sehingga tidak akan menambah sampah plastik. 20\% Lantai hotel tanpa karpet hal ini karena karpet membutuhkan energi listrik yang lebih banyak untuk dibersihkan dan bahan kimia yang digunakan dapat mencemari lingkungan. Sebanyak $\quad 30 \% \quad$ hotel menyediakan Koran berdasarkan permintaan. Hotel memberikan pilihan untuk tamu apakah ingin koran tersedia atau tidak jadi koran tersedia sesuai permintaan tidak setiap kamar di beri. Masih sedikit hotel menyediakan Bahan makanan organik atauproduk lokal yaitu menggunakan bahan-bahan lokal atau membelinya di petani sekitar hotel. Seharusnya Dengan membeli secara lokal, pihak hotel telah menghemat bensin dan waktu untuk transportasi.

\section{KESIMPULAN}

Rata-rata persentase perkembangan hotel berbintang Jawa Timur adalah 16.7\% dan merupakan pekembangan hotel yang paling tinggi. Perkembangan wisatawam nusantara (Wisnus) pada tahun 2013 sejumlah 39.663.005 dan wisman mancanegara 300.090 wisman, naik sebesar $11.78 \%$ dibanding pada tahun 2012 yang jumlahnya 269.943. Lama 
tinggal wisnus adalah 1.7 hari tinggal sedangkan wisman lebih lama yaitu selama 2.5 hari.

Jawa Timur memiliki pintu masuk wisatawan mancanegara yaitu Bandara Juanda dengan urutan ke 5 dalam kontribusi masuknya wisatawan mancanegara ke Indonesia 2.56\% setelah Bandara Tanjung Uban (Bintan - Riau) 3.61\% (Dinas Kebudayaan \& Pariwisata, 2013).

Sebaigan kecil hotel dengan baik menggunakan kembali air bekas mandi untuk menyiram tanaman. Dan 75\% Hotel ramah lingkungan memiliki kebijakan bebas dari asap rokok. Dan masih sedikit Hotel-hotel menempatkan kartu-kartu imbauan seperti penggunaan kembali handuk dan sprei tempat tidur sehingga handuk dan sprei tempat tidur tidak perlu diganti setiap hari. Dengan demikian tamu cukup minta dirapikan kembali.

Belum maksimalnya praktek hotel hijau menerapkan hemat energi dan masih sebagian hotel konservatif masih suka menggunakan lampu pijar. Begitu pula penggunaan pendingin ruangan $(\mathrm{AC})$. Akan tetapi sebagian besar hotel menggunakan pendingin ruangan berjenis VRV air-condition yang dapat mengatur suhu sesuai jumlah orang dalam ruangan dan otomatis mati jika tidak ada orang.

Kesadaran manajemen hotel memiliki keasrian taman atau banyak tanaman cukup tinggi mengingat taman hijau berfungsi untuk membersihkan udara sekitar hotel. Dan masih sedikit Hotel menyediakan dispenser untuk sabun dan shampo. Seharusnya Hotel Hijau menyediakannya dalam dispenser atau wadah isi ulang dan mengabungkan shampo dan conditioner (pelembab rambut) dalam satu produk sehingga tidak akan menambah sampah plastik.

Masih sebagian hotel menyediakan Koran berdasarkan permintaan. Hotel memberikan pilihan untuk tamu apakah ingin koran tersedia atau tidak jadi koran tersedia sesuai permintaan tidak setiap kamar di beri. Dan masih terbatas hotel menyediakan bahan makanan organik atau produk lokal yaitu menggunakan bahan-bahan lokal atau membelinya di petani sekitar hotel untuk menghemat bensin dan waktu untuk transportasi. 


\section{DAFTAR PUSTAKA}

Brooker, G. (1976). The selfactualizing socially conscious consumer.Journal of Consumer Research, 3(9), 107-112.

Clausing, J. (2008). Survey: Boomers more likely to go green in business travel. Travel Weekly, 67(2), 22.

Crocker, M. (2008, July 28). Among leisure travelers surveyed, nearly everyone professes to be green.

Retrieved from http:/ / apps.travelweekly.com/ Multimedia/ consumertrends072808/index.ht $\mathrm{ml}$

Crocker, M. (2008, July 28). Among leisure travelers surveyed, nearly everyone professes to be green.

Retrieved from http:/ / apps.travelweekly.com/ Multimedia/ consumertrends072808/index.ht $\mathrm{ml}$

Dinas Kebudayaan Dan Pariwisata Jawa Timur, 2013, Kebudayaan dan Pariwisata dalam Angka Tahun 2013, Surabaya

Eric.S.W., Chan, S.C.K. Wong (2006), Motivations for ISO 14001 in the hotel industry, Journal of Tourism Management, 27, 481-492

Gubernur, 2012, Banunan Gedung Hijau, Peraturan No. 38 Tahun 2012 Gubernur Provinsi DKI, Jakarta

Kemenpar; http://www.kemenpar.go.id/as p/detil.asp? $\mathrm{c}=16 \& \mathrm{id}=2985$ diakses tanggal 15 desember 2013

Ljungberg, L.Y., 2007. Materials selection and design for development of sustainable products. Materials and Design 28, 466e 479 .

Luttropp, C., Lagerstedt, J., 2006. EcoDesign and the ten golden rules: generic advice for merging environmental aspects into product development. Journal of Cleaner Production 14 (15/16), 1396e1408.

Millar M, Karl JM, Seyhmus B, 2012, Importance of Hotel Hijau Attributes to Business and Leisure Travelers, Journal of Hospitality Marketing $\mathcal{E}$ Management, 21:395-413, 2012

Ni Luh Made, 2013, Gaya hidup yang serba ramah lingkungan bukan sekedar tren, http:/ / travel.kompas.com/ Diakses 14 April 2015

Peattie, K., 1995. Environmental Marketing Management: Meeting the Green Challenge.Pitman Publishing, London, UK.

Pedersen, E., \& Neergaard, P. (2006). Caveat emptor - let the buyer beware!Environmental labeling and the limitations of 'green' consumerism. BusinessStrategy and the Environment, 15, 15-29.

Ray Wang, 2012, The investigation of Green Best Practices for Hotels in Taiwan, Procedia - Social and Behavioral Sciences57 ( 2012 ) 140 $-145$ 
Reinhardt, F.L., 1998.

Environmental product differentiation: implications for corporate strategy. California Management Review 40 (4), $43 \mathrm{e} 73$.

Robert, K.-H., March/April 1995. The natural step. Timeline, 1e24.

Roy, R., Wield, D., Gardiner, J.P., Potter, S., 1996. Innovative Product Development. The Open University, Milton Keynes, UK.

Rully Dwiantoro

:http://mrd93.blogspot.com/20 13/10/manajemen-lingkunganevolusi-perubahan.html

Diakses tgl 14 April 2015

Schmidheiny, S., 1992. Changing course: a global business perspective on development and the environment. In: Business Council for Sustainable Development. MIT Press, Cambridge, MA.

Shrivastava, P., Hart, S., 1995.

Creating sustainable corporations.Business Strategyand the Environment 4 (3), $154 \mathrm{e} 165$.

Simon, F.L., 1992. Marketing green products in the triad.Columbia Journal of World Business 27 (3-4), $268 \mathrm{e} 285$.

Singgih santoso, 2002, Aplikasi SPSS

Pada Satatistik Multivariat, PT

Elex Media Komputindo, jakarta

Sugiyono, 1997, Statistik untuk

Penelitian, Alfabeta, Bandung

Wilco W. Chan, 2009, Environmental

Measures For Hotels'environmental

Management Systems ISO 14001,
International Journal of Contemporary Hospitality Management Vol. 21 No. 5, pp. $542-560$ 